\title{
SUPPORTING THE RE-EMERGENCE OF HUMAN AGENCY IN THE WORKPLACE
}

A New Role for Information System Technologies

\author{
Tony Salvador and Kenneth T. Anderson
}

Intel Research, Intel Corporation

\begin{abstract}
Based on a multi-nation ethnographic study of retail environments, we consider the role of information technologies, specifically ubiquitous computing, in the context of worker agency in the workplace. Agency (not software agents) is defined as the ability of the retail worker to act appropriately but relatively unencumbered by the dictates and wishes of the establishment; in a retail setting, it can mean making decisions based on an understanding of the business. However, rather than supporting workers making decisions, information technologies have been used primarily to rationalize operations (streamline, eliminate variability and gain efficiency) with concomitant reductions of worker agency. We found that an ActorNetwork Theory analysis/synthesis of our data indicated opportunities to reestablish agency. By adapting ubiquitous computing technologies in the context of enhancing agency, we identify and present new and viable interaction paradigms, simultaneously attending to operations imperatives. We argue that new, emerging technologies can and should be designed explicitly to support the emergence of worker agency.
\end{abstract}

Key words: agency, actor-network theory, ethnography, information systems, ubiquitous computing

\section{INTRODUCTION}

Technological innovations, from large glass panes, steel and elevators, point-of-sale (POS) systems and the internet, have enabled a great majority of retail innovations in the last 150 years that have mostly added to - rather than replaced - the panoply of retail categories available to many of us. One of the most recent (last 50 years) technological innovations has been the 
introduction of information technologies especially in the context of streamlining or, rationalizing, retail operations (Meffert, 2000). As technology continues to progress and change, one can only expect retailers to continue along the historical trajectory of incorporating new technologies to further rationalize operations (cf., Williams \& Larsen, 1999).

An intense focus on operations has resulted in obvious advantages for retailers with - perhaps unintended - side effects. Our research suggests that as operations become increasingly efficient and as variability in the system is increasingly controlled, these endeavors tend also to impinge on the retail experience for both the worker and the customer, inadvertently rationalizing that experience in addition to their operations. Rigid and predictable transactions - from the perspective of both the customer and the worker become de rigueur. Human computer interaction becomes increasingly limited to human computer reaction. In short, there's less expression of agency, which can be roughly defined as the ability to impose one's own will in a given network of interacting actors (Latour, 1999).

There has been considerable work examining consumer agency, per se (cf., Sherry et al., 2001; Kozinets et al., unpublished manuscript), There has also been some earlier work on the role of workplace agency such as local innovations by workers sometimes kept secret from management (cf., Orr, 1996; Suchman, 1995). However, there's been very little work on the possibility of technological innovations specifically designed to enhance worker agency while maintaining the rationalization imperative of information technologies necessary for competitive retail environments.

In particular, we find an inverse correlation between the amount of information technology and the expression of worker agency in retail environments. That is, workers, as a part of the retail system, are themselves increasingly rationalized. To remain employed, it's necessary for them to become just another 'cog' (perhaps, 'bit' is more appropriate) in the (information) system. Rationalizing the human worker is, on the face of it, a natural extension of the prevailing role of information technology in retail environments. But it shouldn't be like this; humans should interact with, not simply react to information systems. What're needed are new interaction paradigms, new ways to actively consider the role of information systems in relation to human actors.

The emergence of increasingly viable ubiquitous computing technologies suggests possibilities. Weiser's (1991) paper is perhaps most well known for introducing the concept of ubiquitous computing. Since then, these technologies, have come to include three main capabilities: a) the ability to 'label' people, places and things with everything from passive (no power of their own) radio-frequency identification 'tags', b) the ability to distribute remote and independent 'sensors' to detect environmental stimuli, such as 
noise, temperature, emissions, etc. and c) the ability to combine these two capabilities into small fully functional computing devices that can form networks of communicating sensors and tags (cf., Sakamura, 2002). The general point from the technological perspective is that computing capabilities formerly confined to specific locations, can now be distributed through out the environment, making it possible, for example, to continuously track products from manufacture (indeed, before manufacture) through to the customer purchase with the envisioned further rationalization that inevitably would manifest itself.

In this paper, we consider these technologies in the context of the human worker. That is, while the development of ubiquitous computing technologies continues relatively unabated, its consideration merely as a further tool of rationalization, e.g., supply chain management, obscures the liberating and differentiating potential of the technology that suggests new and novel forms of interaction in the very same environments shared by the very same increasingly rationalized supply chains. By focusing on the human part of the human-computer interaction, we find opportunities for technology to contribute to the reintroduction of human agency in the workplace.

We also limit our discussion to the role of these particular applications of technology in the context of the individual worker as opposed to the role of the technology in the context of the most general business operations, or of the corporation's adoption of these particular capabilities, per se. We feel that further evaluation of this work from a purely business perspective is required before we can begin to comprehend a framework for organizationwide diffusion of these capabilities (Scheepers \& Rose, 2000; Lyytinen \& Damsgaard, 2001).

We present evidence from long-term, multi-nation ethnographic work in a variety of retail establishments and settings. We find a general, perhaps counterintuitive, pattern: workers in establishments that rely more heavily on information systems seem to express less agency then those that haven't incorporated such systems. We consider our evidence within the context an actor-network theoretic approach advocated by Callon (1986) and Latour (1999) and use this theoretical approach to define agency in terms of polimorphic and mimeomorphic actions that technologies can encourage or prohibit (Collins \& Kusch, 1998). By way of illustration we also offer specific technological implementations and discuss their advantages and disadvantages in the retail environments of the future. 


\section{METHODOLOGY}

This paper draws on results of two distinct ethnographic studies of retail environments in addition to ongoing, multi-site, concurrent ethnographic exercises. The first ethnographic study of retail environments (Salvador, Bell, Anderson, 1999) focused on consumers from which we generated four abstractions of shopping experiences along two dimensions. We employed a variety of techniques including observation, participant observation, interviews and auto-ethnography. The second study, with fieldwork conducted in the winter of 2003 , was a primarily observational study of a variety of retail environments along with interviews. In addition, we held innovation and design exercises in situ and used the results of these sessions themselves as data. In this latter exercise, we drew out patterns of innovation that seemed to fit most closely with certain retail environments and less with others. With these, we conducted additional interviews with retail staff. Finally, as a team of six social scientists almost continuously engaged in ethnographic work around the world, it is common practice for us constantly to record images and notes of a wide variety of retail environments.

\section{HABERMAS, LATOUR, AGENCY \& RETAIL}

We start this discussion with the example of a small motorcycle rental shop for tourists in a small town on a Greek island and continue weaving in several more examples of increasing size into our discussion ending with "Red" (not the real name), a very large discount retail chain.

This happened: Two friends were to leave the next morning from Skala Eressos to Sigri, the first leg of a week's trekking holiday around the Greek island of Lesvos. After dinner, walking along the main street, they saw a tourist shop renting motorcycles and thought it wouldn't be at all a bad idea to leave the packs, walk to Sigri and then rent motorcycles to come back and retrieve the packs. It'd be fun anyway. One approached the clerk: "Excuse me, but you do rent these, don't you?" "Yes, certainly." "Do you also rent them in Sigri?" "Why don't you tell me exactly what you are thinking." He told him. "We can do that. We can bring the scooter to Sigri and pick it up later. It will cost you \$20 euros extra", which opened the negotiation for price.

We've defined agency as the ability of the retail worker to act appropriately but relatively unencumbered by the dictates and wishes of the establishment. Our Greek clerk did just that. Such a delivery service was not a formal part of the shop's operations, but given the time of year 
(Spring), and low demand for that time of the week (Wednesday), the clerk knew his capabilities and was able to make an offer to the tourist and initiate a negotiation.

There's real power in being able to custom design a service for a particular client on the spot. And there are loads of similar examples: special orders in the fish markets in Nantes France, intense negotiations for prices and packages at Tech Mart in Seoul, South Korea and free beverages for special guests in the ferias of Santiago de Chile.

In all of these examples, the clerks had no access to any information technologies in support of their ad hoc arrangements. We note, therefore, that agency flourishes in the absence of information technologies. Do we find more agency or less with larger retailers replete with information systems? What we actually find is that higher prevalence of information technologies coincides with a lower prevalence of expressed agency. It's not that the technology limits the expression of agency by design, but rather, the design of the technology is to rationalize operations, supporting its management designers; that agency is limited as a byproduct of that design is unfortunate.

The issue has theoretical importance. In the past, Habermas (1970), as discussed by Whitley (1999), argued that humans alone possess and can express agency, and information systems (machines) do and cannot. Moreover, information systems (machines) are to be made merely to serve human needs. This is precisely the way information systems, for the most part, are designed today- especially in retail. But they don't necessarily have to be. It's a matter of adopting a deliberately different outlook.

Actor-Network Theory (ANT) offers such an alternative view. ANT asserts that in any system there are only "actors" and that agency is expressed as an emergent property of the interaction among the actors expressing their will one on the other (Latour, 1999). Phrased slightly differently, agency is not expressed at the "nodes", i.e., (only) by the actors, but rather as transformations that result from the interaction of all the actors in the network, including the information systems. Agency is, therefore, an emergent property of the total system. It's less important for the design of interaction whether the theory is "true" or not, but whether it is useful. ANT is a very useful theory for thinking about the designs of information technologies.

Since actors act, and since we've defined agency as actions of a particular type, we must also define what it means "to act". Identifying what action means will directly inform the sorts of technological innovations that can enhance or hinder agency. For this, we turn to some recent work by Collins \& Kusch (1998) in which they define two types of actions: polimorphic and mimeomorphic. Basically, polimorphic actions (poli- from 
the root for polis, of the people, and not only from the root poly-, as in many) are those that can only be understood - or done - by other people who are functionally members of the same society. Mimeomorphic actions are those that if replicated by someone who didn't understand the action would still look the same as if someone who did understand was performing the actions. Put in their terms: polimorphic actions are defined such that only the enculturated can see sameness whereas enculturated and nonenculturated can see sameness in mimeomorphic actions. Action and behavior map onto social and natural kinds. Polimorphic actions can only be described in terms of social kinds. Behaviors - non-intentional acts, such as blinking your eye - can be described in terms of natural kinds.

In retail, the social kinds are inscribed by the actor-network of the retail establishment and by the mores of commercial/market transactions in general. What a customer might see as reasonable and what the retail worker may see as reasonable are trumped by the power of the corporate retailer. The corporate retailer actor has the power to impose its will on the actors in the store and the information systems are not only a means of translating the corporate retailer's will onto the workers and customers, but exert their own will in addition. Subversive activities of customers (e.g., shoplifting) or clerks (e.g., workarounds) are their means of translating their will onto the network.

We can, thus, modify our definition of agency as "the ability of the retail worker to act appropriately but relatively unencumbered by the dictates and wishes of the establishment by engaging in a greater proportion of polimorphic actions as compared with mimeomorphic actions". Our question, then is to consider the types of technological innovations that explicitly support polimorphic actions - that is, those actions based on an understanding of the relevant culture/society, i.e., the retail environment.

Consider the example of Juliet, an interior designer with "Blue" (not the real name), a large chain of high-end furniture stores. Blue has a fairly unique business in that they control the design, manufacture, distribution, sales and financing of their furniture. One implication, for example, is that many of the 1500 different fabrics can be upholstered onto any piece of furniture, where many retailers limit the selection from three to perhaps a dozen.

Most, if not all, of the clerks in Blue stores are interior designers, called design consultants, who work entirely on commission. Blue provides them with, in essence, an office, equipment and a default client list. When we arrived, Juliet was with a client together at a computer. To assist the design consultant and the customers, the corporation provides a computer system that, in the Juliet's words, "enhances the customer's imagination" by being able to show images of all furniture in all fabrics, rendered in real time and 
visible on the computer monitor. Juliet, on the whole, was content with the system and found it very helpful when talking with her clients.

We also learned that she often meets customers in their homes to consult on the interior design and consider possible Blue products. As a designer, it often helps to see the physical space and she often brings printed copies of items she's assembled (fabrics rendered on a particular furnishing) with her when she goes into clients' homes. While Juliet is pleased with the computer system, she expressed interest in being able to download and use the "imagination" software on a laptop at the customer's residence to, "further help the customer imagine the room with new furniture in it". Recognizing the company was unlikely to provide a laptop, she offered to use her own personally owned computer, but at the time of our engagement, the company was unwilling to make such provisions and it was unclear that it could for policy, technical or legal reasons.

Juliet actually has quite a large degree of agency. However, rather than enhance her agency, this otherwise liberating software conforms to the rational demands of the company's operations and forces her to modify and restrict her behavior, relegating her to an increasingly mechanistic role - in this case simply by restricting her movement to being in front of a particular computer with the customer at a particular time. Her frustration, expressed through her affect more than through her words made it clear that the system was not designed by her or even with her assistance.

Finally, we consider the worker agency at Red discount department stores, certainly the retailer mentioned in this paper most well endowed with information technologies as well as the largest overall, with more than 1100 stores in more than 45 US States. In this case, we observed in several stores, interviewed two former store managers and went on an "ethnographic tour" with one to both a Red store and a primary competitor.

The information system pervades the entire store, linking the store to headquarters, to other sites, such as distribution warehouses, and going so far as to guide the day to day and, at times, minute to minute activities of most store employees. The primary role of the information system is emphatically to manage operations- inventory, shelf stock, sales, distribution, etc. The systems offer corporate management a large degree of control over a farflung enterprise. Red stores, for example, designed according to particular models drawn from among several types with all specific instances of each type being nearly identical one to the other.

The store design includes the physical structure as well as such details as the exact location of shelving units and even product placement, including shelf number, the depth of product on the shelf (how many deep), the number of product along the aisle (facing), etc. The information system accounts for example, for a particular model of soccer ball that belongs on a 
particular shelf, that are stocked three deep and four across and that there should be exactly 12 on the shelves - unless there's a change, in which case the information system will inform the store manager and his/her crew.

Shelf stocks are refreshed on the floor three times as day at prescribed times and workers are required to restock at that time - a goal being to keep as much of the store operations like restocking "off stage" as much as possible. The information system accounts for that, embodying and extending the power of corporate management to control the operations of each store and to eliminate as much variability as possible, homogenizing each store for a fabulous brand experience. The ideal is that the workers will conform to the demands of the system, a proxy for corporate management, of whom their store manager is, him/herself just a proxy as well.

Of course, the ideal is not always achieved. And there's ample evidence in the literature to suggest that workers create their own, albeit private, innovations (Suchman, 1995). However, the store managers indicated that a large part of their job is to maintain the desired order in the store not only as a means of establishing order, but also as a means of establishing the company's brand identity and distinguishing itself relative to other similar retailers. One large discount store on its own website states that differentiating their brands is "...central to [their] ability to continue to generate sales and profit growth at each of [their] divisions", (Target, 2003). The order demanded of the information system comprises more than simply efficiency, it's a part of the core identity.

There is, therefore, a certain amount of risk when violating the system. For example, one store manager told us that while he has some leeway to go off-grid, as it were, like the ability to put shovels in a main aisle during and after a snowstorm, even though according to the rules, product should not ever be placed in the main aisle. While snow shovels in plain view during a snowstorm seems obvious, placing other items in temporary displays does not conform to the requirements expressed by the information system and therefore is undesirable in general - even if it too makes sense. According to the store manager, "You can do it, but if you do and get caught, it better have been profitable. And even then, it's questionable."

The Red information system is designed specifically to rationalize the company's operations. But even Blue's system, though designed to aid the imagination, confines the worker to the desktop. Overall, there is either relatively little expression of worker agency or agency is constrained by the demands of information systems or both. Walmart, at this time generally regarded to be at least among the largest retailers in the world - if not the largest - even goes so far as to use it's market strength to encourage other corporations to conform to their information systems, reducing even the expression of agency by corporate management from other companies. Is it 
possible to have both efficient and rational operations with a greater degree of worker agency? It's this question we address in the last section.

\section{EXAMPLE CONCEPTS}

Our goal is to identify technological innovations that accommodate the business requirements of the retailer while also providing an appropriate foundation for encouraging the emergence of agency. In particular, we advocate developing technologies that encourage an increasing proportion of polimorphic actions for retail workers. We've already seen several examples of polimorphic actions our ethnographic portraits: the Greek motorcycle entrepreneur making ad hoc arrangements for the trekkers, putting shovels in the aisle during a snowstorm at Red, Juliet heading to her client's homes and offering her own laptop for "corporate" use. Here we rely on the emergence of ubiquitous computing technologies to begin developing alternative interaction paradigms for retail environments that encourage a rise in the proportion of polimorphic actions by clerks. We must caution that nearly anyone reading this paper will have his/her own experiences with retail environments. In addition, retail environments are highly variable. What might work in one, might fail miserably in another. One must be careful not to evaluate the ideas relative to one's personal feelings, but in light of the current context of supporting agency.

\subsection{Yield Management}

While yield management (variable pricing according to demand) has been prevalent in the airline industry for some time, it's only recently beginning to be tried in retail establishments. For example, Stelios HajiIoannou, who, among other endeavors, began a string of companies beginning with the prefix "easy", easyJet, easyEverything, etc., has recently announced easyCinema, which will offer theatre seating at variable rates depending on the movie, the time you buy it, the demand, and other variables; easyEverything varied internet access pricing by time of day.

One possible application of ubiquitous computing technologies would be to encourage real time yield management akin to the Santiago's feria or the Greek motorcycle shop. Mimeomorphically, by using ubiquitous computing technologies (e.g., sensors \& tags) and sophisticated algorithms, one can offer dynamic pricing depending on where people are in the store or the time of day, or perhaps better, the time of day and the number of people in the store. The sensors can report to the information system about what's been picked up, for example, the number of times, etc. The clerk, who sees 
people gathered in a spot could see a potential opportunity and engage in a dialog with the information system, suggesting that an immediate price drop might be appropriate given the current conditions. The system could provide probabilistic expected returns, and the clerk can consider these, but also consider the human elements in the store - what's been said, the behaviors of the customers, who they are or look like they are, etc., and make a decision. Of course, the decisions are tracked and the clerk's performance is evaluated.

It's a very different sort of interaction. One imagines the dialog happening discretely, perhaps with a handheld device, or ever verbally though one of the increasingly prevalent headsets seen on clerks. It also permits the clerk to initiate an action in conjunction with algorithmic interpretation, combining positive attributes of both information systems and human awareness, or, I daresay, intuition. It also allows the clerk to initiate a positive personal interaction with some customers.

Of course, in some contexts, this arrangement might be inappropriate. However, a hallmark finding of both our work and the intentions of the retail industry, as we discussed especially with regard to Red, is idiosyncraticity and diversity to create identity, brand and distinctiveness. It's not difficult to imagine a wide variety of sensors and tags deployed for a wide variety of purposes and supported by an even wider variety of algorithms

For example in one variation, suppose there's a group of people in the store and the clerk can tell - you know - there's a certain buzz, people "want to buy" but are looking for some prompting, something to get them over the decision. Clerks could, for example, offer an instant sale - maybe one of a variety that are vetted by the information system: "If we sell 10 pairs of jeans in the next 20 minutes, you all get $20 \%$ off." Or suppose sensors detected that a fair number of people have looked at a certain item in the shop, but then returned it to the rack or shelf. Clerks, having been alerted by the information system, could make (subtle) inquiries and could, if appropriate, initiate an instant sale.

Of course, information systems as actors in the network could do something like this sort of thing on their own, but these systems would miss "the buzz", they would rely on attributes available to computing systems which are not at all the same sorts of attributes available to human actors. They have - and will continue to have - immense difficulty in making subtle and suitable inquiries and detecting meanings in subtle human behaviors and likely as not, there'd be an unacceptable number of false positives and perhaps more insidiously, false negatives.

In addition, having clerks actually get involved and make the decisions, albeit with information systems support, not only invests them in their job, but also encourages a greater relationship between the consumers and the 
retailer (Fournier, 1998) and between the retailer and the clerk. In these examples, the clerks had to agree to the initiating the "instant sale"; one imagines that their performance would be kept and one could link their bonus pay to their performance, sharing the profits with them. Weak performance might limit their participation in the program or increase their training. Responsibilities come with agency.

\subsection{Clerk Relations}

Orr (1996) demonstrated that copy machine mechanics swapped stories of repairs at coffee breaks. He went on to provide the ability for copy mechanics to be in continuous contact with one another so that should one request help on a particular issue another might be able to assist. One can imagine similar capabilities for clerks in retail establishments with communications carried through the IT systems in the store and between stores.

There's a lot happening in a large retail establishment. It's difficult for clerks to be everywhere and to help everyone and still take care of the minute-to-minute store operations. It's also difficult for clerks to learn from each other and aid each other on a moment's notice. Clerks should be able to talk with one another in the store requesting and providing assistance as necessary. Some retailers already do this, providing for a private communication network rather than broadcasting requests over a public address system as well as maintaining increased surveillance.

One can enhance such systems for a wider variety of purposes. In a particular shop, clerks could offer assistance to others when customers have questions about products. Or the clerks could be connected to other shops in the same corporation and request assistance on the spot. Or, the information system can track the sorts of expertise clerks have and make the connections for a clerk that requests assistance - sort of like a "match making" service, but matching clerks to customers, drawing immediately on the knowledge spread through the corporation. Clerks might, over time, gain a reputation.

If we imagine that shelves are provided with electronic displays, clerks could also get increasingly involved in making recommendations. At Powell's Used and New Bookstore, in Portland, Oregon, employees write short reviews of books they read and put a small placard along the edge of the shelf near the book. Many purchases are heavily influenced by stories of individual experience - of the customer, of the employees and second hand as reported by other customers, employees and their friends (Keller \& Berry, 2003). Capturing these stories at the point of sale, editing and attributing them to particular clerks can provide an ongoing narrative associated with a particular product. Customers should also be able to leave their experiences, 
again, further involving the customer and clerk actors in the network. In one instantiation, this information could be provided on hand-held or stationary displays/tablets. Customers can find clerks' or other expert customers' comments at these stations - maybe by passing the product near a stationary display or, if the display is also a reader, passing it near the products, which have the tags.

\section{SUMMARY}

All of these sorts of ideas challenge the extant models of in-store shopping. Shopping is indeed a learned activity (Cohen, 2003) and we are not suggesting that such changes happen overnight, nor that these particular ideas should become manifest. Rather, we are proposing these concepts as particular examples of technologies that are not necessarily geared toward improving the efficiency of the retailer's operations, but toward the notion of a different direction for technological innovation and importantly, a different type of human-computer interaction with information systems.

In these two examples, we demonstrate the possibility of information technologies, specifically ubiquitous computing, being differently designed to support the emergence of agency in an actor-network, in this case, in retail establishments. We specifically attempt to show that when consciously considered, it's possible to imagine technologies supporting polimorphic actions in concert with an information system as agentic partners in the actor-network.

Would retailers endorse these sorts of innovations? Would customers participate? One can argue if there's a viable business model, they very well might. Of course, retail spaces are different, one from another. An innovation in one establishment would be a distraction in another. But differentiation is a key component of the retailers' endeavors. And information systems applied for the continued rationalization of their operations can only serve to rationalize more and more of the retail experience. Ubiquitous computing technologies, far from being limited to improvements in supply chain operations, can and should be actively and consciously considered as new technologies that provide for new and innovative interaction paradigms.

\section{REFERENCES}

Callon, M., The sociology of an actor-network, in M. Callon, J. Law \& A. Rip, Mapping the dynamics of science and technology, Macmillan, London, 1986. 
Cohen, L., A consumers' republic. Alfred A. Knopf, New York, 2003.

Collins, H. \& Kusch. M., The shape of actions: What humans and machines can do. MIT Press, London, 1998.

Fournier, S., Consumers and their brands: Developing relationship theory in consumer research. Journal of Consumer Research, 24, (1998),343-373.

Habermas, J., Toward a rational society: Student protest, science and politics (Jeremy J Shapiro, Tranlation), Beacon Press, Boston, 1970.

Hernandez, M \& Iyengar, S.S., What drives whom? A cultural perspective on human agency, Social Cognition, 19(3), (2001), pp. 269-94 http://www.columbia.edu/ ss957/ whatdrives. $\mathrm{html}$

Keller, E. Berry, J., The Influentials: One American in Ten Tells the Other Nine How to Vote, Where to Eat, and What to Buy, Simon \& Schuster, New York, 2003.

Kozinets, R.V., Sherry, J.F., Storm, D., Duhachek, A., Nuttavithisit, K., Deberry-Spence, B. The screen play of media spectacle: Dimensions of ludic consumption at ESPN Zone Chicago, unpublished manuscript.

Latour, B. On recalling ANT, in Law, J. \& Hassard, J. Actor Network Theory and After, Blackwell Publishing, Oxford, 1999.

Lyytinen, K. \& Damsgaard, J. What's wrong with the diffusion of innovation theory, in Proceedings of the IFIP TC8 WG8.1 Fourth Working Conference on Diffusing Software Products and Process Innovations, Kluwer, Netherlands, 2001.

Meffert, H. Consumers Tomorrow, ECR Academic Report (2000), 68-71. http://www.ecrjournal.org/partnership/publications/report2000/10_Consumers.pdf

Orr, J. E., Talking About Machines: an ethnography of a modern job, IRL press, Cornell University Press, Ithaca, 1996.

Sakamura, K. Making computers invisible, IEEE Micro 22(6), (2002), 7-11.

Salvador, T., Bell, G. \& Anderson, K., Design Ethnography. Design Management Journal, 10(4), (1999).

Scheepers, R. \& Rose, J. Understanding ubiquitous IT in organizations: the case of intranet introduction, in Svenson, L., Snis, U., Soresnen, C., Fagerlind, H., Lindroth, T, Magnusson, M \& Ostlund, C. (Eds), Proceedings of the 23rd Information systems Research In Scandinavia (IRIS), Lingatan, Sweden, 2000, 597-609.

Sherry, J.F., Kozinets, R.V., Storm, D., Duhachek, A., Nuttavithisit, K., Deberry-Spence, B. Being in the Zone: Staging retail theatre at ESPN Zone Chicago, Journal of Contemporary Ethnography, 30(4), (2001), 465-510.

Suchman, L. Making work visible. Communications of the ACM, 38 (9), (1995), 56-64.

Target Website http://www.targetcorp.com/targetcorp_group/companies/companies.jhtml Weiser, M. The computer for the $\mathbf{2 1}{ }^{\text {*t }}$ century. Scientific American, 265(3), (1991), 94-101.

Whitley, E.A., Habermas and the Non-Humans: Towards a Critical Theory for the New Collective. Critical Management Studies conference, Manchester, (1999). http:// www.mngt.waikato.ac.nz/ejrot/cmsconference/documents/Information\%20Tech/Habermas $\% 20$ and \%20the\%20non-humans.pdf. 